\title{
A Model for Location of Fresh Agricultural Products Logistics Center Based on Customer Satisfaction
}

\author{
Xin Zhu \\ Department of Management \\ Guangxi University of Science and Technology \\ Liuzhou, P.R.China \\ 5266736@qq.com
}

\author{
Tengfei Zhang \\ Department of Management \\ Guangxi University of Science and Technology \\ Liuzhou, P.R.China \\ 729225265 @qq.com
}

\begin{abstract}
Along with the importance of logistics industry, the location of fresh agricultural products has important significance. In view of the easy loss characteristics of fresh agricultural, and measure the level of service with customer satisfaction of time. Considering the total cost of logistics and customer satisfaction, we establish a multi-objective optimization model for location of fresh agricultural products logistics center.
\end{abstract}

Keywords-fresh agricultural products; distribution center; customer satisfaction

\section{INTRODUCTION}

\section{A. The Concept of Distribution Center}

Distribution center accept a large number of goods from suppliers, packaging, sorting, storage, distribution, processing and information processing and other operations, then, in accordance with the requirements of the order of many who need to get ready goods, works at a satisfactory level, for distribution facilities. Distribution Center is a Terminal logistics node facility, distribution and delivery through effective organization, to complete the final allocation of resources, is a labor-based, comprehensive, complete and modern delivery activities. Goods from production to wholesale and retail outlets and, ultimately, the flow of sales to consumers, generally to distribution centers in some classification, custody and distribution processing, processing, distribution center has become a link connecting production and retail ${ }^{[1]}$.

\section{B. Functions of the Distribution Center}

Distribution center is a modern logistics infrastructure ,it is set of goods packaging, processing, storage, handling and many other services, and it is the logistics center distribution of goods as the main functions of the executive.

1) Function of consolidation: Consolidation functions are the most basic function of the distribution center. Distribution centers and supply point for the supply of goods set for the corresponding logistics operations, such as warehousing, processing, packaging, and distribute according to the different needs of users. Distribution center play is a function of consolidation functions before the goods were transported to customer; it must have in order to warehouse-based storage facilities, capable of a variety of goods for safekeeping, storage and so on.

2) Function of processing and packaging: Processing and packaging functions is an important function of the distribution center. After the goods are focused on the distribution center, most of them should be carried out with varying degrees of processing and packaging, so you can make more efficient distribution of goods, so as to provide customers with fast delivery time.

3) Function of Sub-goods: Sub-goods are the core function of distribution center. Distribution center is an intermediary service structure, cargo distribution center after concentration and logistics operations, will eventually be in accordance with the requirements of the demand points corresponding goods, and then distributed to the various demand points.

With the development of the national economy, the logistics industry has been paid more and more attention; many cities have the logistics industry as a focus on the development of the industry. With the development of logistics industry, people face a common problem: how to carry out the reasonable selection of distribution center. In the logistics network, distribution center is connected between the supply and demand point, is a bridge between the two, and plays an important role in the logistics system, logistics distribution center, the reasonable location can save costs, speed up the flow of goods, logistics enterprise's income increase. Therefore, the strategy of distribution center site selection is a very important issue for the optimization of the whole logistics system.

\section{PROBLEM PRESENTATION AND RESEARCH STATUS}

\section{A. Problem Presentation}

Fresh agricultural products are very sensitive to the time factor, exhibits a high timeliness, this is mainly because that fresh agricultural products have a short shelf life, perishable, can't be stored at room temperature for long-term ${ }^{[2]}$. It mainly consists of fruit and vegetables, meat and aquatic products, and so on. According to statistics, China has 400 million tons per year of fresh produce into circulation, while at the same time accompanied by huge losses. Annual decay rate of meat is $15 \%$, decay rate of vegetable is up to $20 \%-30 \%$, while the decay rate is only $5 \%$ of Europe and the United States, 
resulting a loss of more than 100 billion of fruits and vegetables in only one year. This situation is mainly caused by two reasons: First because of the characteristics of fresh agricultural products of its own, even if refrigerated storage and transportation will still have a certain amount of loss ${ }^{[3]}$; Second, China's large-scale, systematic cold chain transport system has not yet been formed, compared with the development of modern agriculture and consumer demand is still lagging behind. According to the "agricultural products cold chain logistics development planning" in the "Twelfth Five Year Plan", which been promulgated by the national development and Reform Commission, we will build a batch of efficient, large-scale and cross-regional cold chain logistics distribution center of new technologies by 2015 .

Due to the distribution center location decision is not only directly related to the future distribution centers their operating costs and service levels, but also to society as a whole the rationalization of logistics systems, distribution center location is a critical issue in planning distribution center construction project. While distribution center location decision belongs to the long-term planning of logistics system, building location if you selected will be difficult to change, usually in the distribution center location decision to fully consider a number of factors, which makes the location problem of distribution center are generally very complex, difficult to resolve, you typically need to seek the most appropriate solution.

\section{B. The Present Situation of Study}

About the location problem of fresh agricultural product logistics center, most of the existing studies regard the agricultural products as perishable products to processing, the transportation cost, fixed cost and loss cost to a minimum from the angle of metamorphic loss. Wang Zhenzhong applied AHP, hierarchical structure model is established with multi factor, constructing judgment matrix, obtained the influence of distribution center location of the most important factors, combined with examples, and provides the decision scheme optimization ${ }^{[4]}$. Xie Xiaoliang established a mixed integer distribution center location model from the perspective of the rate of deterioration, and numerical examples show the rationality and feasibility of the model and algorithms ${ }^{[5]}$. In order to save the operating cost and minimal investment costs as the goal, Qiu Rongzu establish the mathematical model of multiple distribution center location problems with time constraints based on fresh produce shelf short features ${ }^{[6]}$. Qu Bo presents fresh farm products cost-benefit equilibrium model of price changed over time from the perspective of costbenefit balance, and in the case of revenue goals to determine, establish the number and location of the distribution center, and minimize its costs ${ }^{[7]}$. With the deepening of research, Zhang Jian pointed out that the product fresh degree affect the market demand, established the model of location on this basis and gave a numerical example ${ }^{[8]}$. Zhu Rongrong considering the logistic cost and service reliability, established multiobjective optimization of cold chain logistics distribution center location model and verified its feasibility and versatility [9]. Chen Jia using Flexsim simulation software simulation model of logistics distribution center system construction on agricultural products, in the simulation model on the basis of, to produce vegetables, for example, by modifying model structures and parameter, improve the efficiency of its operations and provide decision support for farm products logistics and distribution center ${ }^{[0]}$. According to the characteristics of fresh agricultural products, fresh loss coefficient and response time satisfaction function are been introduced. Xiao Jianhua established the fresh produce distribution center location model based on the timeliness and responsiveness and verify the validity of the model [11]. However, we found that most of the existing researches just consider the total cost to a minimum; few have emphasized customer service satisfaction. Based on the above considerations, this article introduces the concept of customer service satisfaction, and it will be introduced into the model, build customer satisfaction considered location model, this model is more in line with consumers' actual consumer purchases.

\section{DISTRIBUTION CENTER LOCATION MODEL CONSIDERING CUSTOMER SATISFACTION}

\section{A. Problem Description}

Assume that in a certain area, the number of customers and candidate logistics distribution centers are $N$ and $M$, individual customer needs for the same single product, and demand is known. Due to the impact of delivery mileage, agricultural products will deteriorate while some loss of, and distribution of time could affect customer satisfaction. So the location strategy is to choose a set of candidate-building distribution centers, makes the various expenses of the distribution center total at least, while the maximum customer satisfaction index.

\section{B. Related Assumptions and Model Symbol Description}

- Let $B_{\mathrm{j}}(i=1,2, \ldots, M)$ be a set of candidate logistics distribution centers, their positions are known. Let $F_{i}$ and $V_{i}$ be a set of fixed costs and capacity, they are all known.

- $\quad$ Let $U_{j}(j=1,2, \ldots N)$ be a set of customers, $d_{j}$ stand for the demand of each customer, customer can only accept delivery of one distribution center. Let the delivery speed be $v$, freight units be $c$, the distance between Distribution center and customer demand point be $S_{i j}$, These variables are determined number.

- Operating costs of Distribution Center just associated with the transit of goods, $b$ says the unit operation cost of distribution center.

- The fresh agricultural products will loss constantly during transportation, $\theta$ means corruption rate coefficients, $p$ represents the value of per unit of product.

\section{Customer Satisfaction and its Calculation Method}

Customer satisfaction is reflected in the customer's State of mind; it comes from the comparison of consumption of a service when the customer experience with his heart expected 
conducted. And for distribution centers, the main factors affecting customer satisfaction is the logistics service arriving on time ${ }^{\text {12] }}$. When customers purchase products, they expect to get in a certain period of time, if the product can be timely delivery to the customer, the customer will feel very satisfied. Different distribution center processing different ability, while different customer expectations at different times, as after a certain time, customer satisfaction will drop rapidly; when time excess the acceptable maximum time, the customer will be very dissatisfied. We establish customer satisfaction function according to the customer's requirements for time:

$$
F\left(t_{i j}\right)=\left\{\begin{array}{lcc}
1 & \text { if } \quad t_{i j} \leq L_{j} \\
U_{j}-t_{i j} / U_{j}-L_{j} & \text { if } \quad L_{j}<t_{i j}<U_{j} \\
0 & \text { if } \quad t_{i j} \geq U_{j}
\end{array}\right.
$$

we can come to the integrated customer satisfaction formula according to (1)

$$
F_{\text {total }}=\frac{\sum F_{j} d_{j}}{\sum d_{j}}
$$

It is clear that $F\left(t_{i j}\right)$ means customer satisfaction function, $t_{i j}$ means the transportation time from logistics center $i$ to customer $j \cdot L_{j}$ Says the acceptable longest waiting time when customer fell satisfied, $U_{j}$ represents the shortest waiting time when customer fell unsatisfied.

\section{The calculation of Decayed Value}

We use $W_{i j}(0)$, the initial shipment weight for standard to calculate transport costs and operating expenses, because of the corruption, during the course of transportation:

$$
\frac{d W_{i j}(t)}{d t}=-\theta W_{i j}(t)
$$

While

$$
W_{i j}\left(t_{i j}\right)=d_{j}
$$

We can come to a conclusion that initial shipments in the condition of meeting the needs of customers

The value of the loss

$$
W_{i j}(0)=e^{\theta t_{i j}} d{ }_{j}
$$

$$
f=p\left[W_{i j}(0)-W_{i j}\left(t_{i j}\right)\right]=p d_{j}\left(e^{\theta t_{i j}}-1\right)
$$

\section{E. Establishment of a Distribution Center Location Model}

The location problem of distribution center is selected the best from alternatively, so that the fixing construction cost, operation cost, transportation cost and freight loss cost of distribution center and the minimum, at the same time, the integrated customer satisfaction formula is maximum.

Optimization model of distribution centers location is as follows:

$$
\begin{aligned}
\min U= & \sum_{i=1}^{m} \sum_{i=1}^{n}\left[e^{\theta_{i j}} d_{j} c S_{i j}+p d_{j}\left(e^{\theta_{i j}}-1\right)+e^{\theta_{i j}} d j b\right] A_{i j} \\
& +\sum_{i=1}^{m} F_{i} Z_{i} \\
& \max F_{\text {total }}=\frac{\sum_{i=1}^{m} \sum_{j=1}^{n} F\left(t_{i j}\right) d_{j} A_{i j}}{\sum_{j=1}^{n} d_{j}}
\end{aligned}
$$

s.t.

$$
\sum_{i=1}^{m} A_{i j}=1, j=1,2, \cdots n
$$

$$
\sum_{j=1}^{n} d_{j} A_{i j} \leq V_{i}, i=1,2, \cdots m
$$

$$
\begin{gathered}
t_{i j} Z_{i} A_{i j} \leq U_{j}, i=1,2, \cdots m, j=1,2, \cdots n \\
Z_{i} \in[0,1], i=1,2, \cdots m
\end{gathered}
$$

$$
A_{i j} \in[0,1], i=1,2, \cdots m, j=1,2, \cdots n
$$

Equation (4) means every customer needs only one distribution center and distribution;(5)means the limit capacity of distribution center;(6)means the delivery time must be allowed within the scope of the customer time;(7)and(8)says the decision variables of $0-1 ; Z_{i}=1$ means we should build distribution center at position ; while $Z_{i}=0$ means not; $A_{i j}=1$ means produce Transported from $i$ to $j ; A_{i j}=0$ means not.

\section{THE SOLUTION OF THE MODEL}

For multi-objective model, generally there is no single optimal solution, but a solution of one or more groups exist. We usually solve the problem by turn the multi-objective problem into a single-objective optimization problem through a certain method.

For this model, the main objective method can be used. Choosing the minimize of total cost or maximum customer satisfaction as the main target, and the other just to meet certain requirements. In this paper, we choose the maximum 
customer satisfaction as the main objective to solve the model, function model is:

$$
\max F_{\text {total }}=\frac{\sum_{i=1}^{m} \sum_{j=1}^{n} F\left(t_{i j}\right) d_{j} A_{i j}}{\sum_{j=1}^{n} d_{j}}
$$

Another becomes a constraint condition, $\min U<C$, $C$ means the acceptable highest cost. This problem can be converted to how enable customers to maximize satisfaction under a certain cost. The model belongs to a mixed integer models are NP problems can be solved with LINGO ${ }^{[13]}$, solving steps are as follows:

Step 1: Distribution Center candidates are selected from the known fixed costs a minimum of one, for $k=1$, make it service for all customer, calculate the total costs and customer satisfaction;

Step 2: If the distribution center total cost is less than $C$, then output the results, to step 3;

Step 3: After selecting a distribution center, pick up the least fixed costs for the rest of the candidates. For $k=2$, make both of them service for all customer, calculate the total costs and customer satisfaction, to step 2.and so on, until the total cost reaches $C$.

\section{CONCLUSIONS}

In this paper, logistics distribution center location model based on traditional and added to the total cost of the fresh product loss costs and transit costs, while taking into account distribution center services through customer satisfaction , establishes multi-objective maximum to minimum total cost and customer satisfaction location model. By determining the reasonable distribution centers not only can satisfy the customers of small batch and multi varieties, short delivery time requirements, improve the efficiency of logistics services and customer satisfaction, but also can reduce the stock, the transportation of large-scale, reduce manpower costs, thereby reducing the total cost of logistics.

The location model has great theoretical significance for optimizing the logistics of agricultural products, reduces the loss of value and higher the levels of consumer satisfaction. But the fresh agricultural products logistics distribution center location problem is a complex issue, not simply be considered cost and service can be, for example, a rival and the reasonable location, therefore, whether in theory or in practice has to be further studied in the more mature.

\section{ACKNOWLEDGMENT}

This research is supported by the Foundation of Guangxi Educational Committee (Grant No: SK13ZD030).

\section{REFERENCES}

[1] Gao Zhenhua.Research on The Location Models and Algorithms of Distrbution Centers[D]. Nanjing:Southeast University,2006
[2] Xu Xiangjin, Cao Jie. Location Problem of Fresh Farm Produce Distribution Centers [J]. Logistics technology2012(01), 14-16.

[3] Li Jiaxi. particularities of the fresh food distribution centers [J].China logistics \& procurement, 2007 (7), 57.

[4] Wang Zhenzhong. Investigation and application of Analytic Hierarchy Process in the selecting of address of the Distribution Center[J]. Logistics engineering and management,2010 (01) 97-100.

[5] Xie Xiaoliang, Fu Zhuo. perishable agricultural products logistics distribution center location optimization [J]. Guangdong agriculture science, 2009 (5), 224-226.

[6] Qiu Rongzu, Zhong Xiaoyan. Study on Optimization of Fresh Agricultural Product Distribution Cen ter Location Based on Ant Colony Algorithm [J]. Journal of Jiangnan University (natural science Edition), 2010 (2), 156-161.

[7] Qu Bo,Yang Chao,Zhang Min,Dong Peng. Cost Benef it Equilibrium Model of Logistics Distribution Centre for the Fresh Agricultural Products[J].Journal of WUT(Information \& Management Engineering),2006 (4) 121-124.

[8] Zhang Jian, Fu Shaochuan. Study on Location of Fresh Food Distribution Center with Demand Influenced by the Freshness [J]. Chinese journal of Management Science, 2011,473-476.

[9] Zhu Rongrong, Hu Dawei. A Multi-objective Optimization Model for the Cold Chain Distribution Center Location Problem [J]. Logistics technology, 2012 (01) 108-110.

[10] 0Chen Jia,Jiang Guoliang,Xu Guangyin. Simulation on logistic distribution center system of agricultural products based on Flexsim[J].Journal of Hennan Agricultural University,2011 (2) 258-262.

[11] Xiao Jianhua,Xionghuan. Fresh Farm Produce Distribution Center Location Model Based on Timeliness and Responsiveness[J]. Logistics technology,2011 (1) 32-35.

[12] Feng Yanfang. Establishment of Influence Factor Evaluation Index System of Logistics Service Customer Satisfaction [J]. Logistics technology, 2014 (01) 242-244.

[13] Wu Limin. A Multi-objective Optimization Model for Distribution Center Location Based on Customer Satisfaction [J]. Logistics technology, 2014 (06) 95-97. 